\title{
Lessons from practice: assessing early progress and success in river rehabilitation
}

\author{
Jonathan Matthews • Bart Reeze • \\ Christian K. Feld • A. Jan Hendriks
}

Received: 9 February 2010/Revised: 10 July 2010/ Accepted: 18 July 2010/Published online: 3 September 2010

(C) The Author(s) 2010. This article is published with open access at Springerlink.com

\begin{abstract}
This article comprises a literature analysis of 41 river rehabilitation projects to assess the shortterm (5 years) ability of indicator groups to demonstrate progress towards river rehabilitation goals. Positive indications were compared to land-use, river size, rehabilitation intervention and time. A questionnaire was developed to investigate river manager's interpretation of rehabilitation success and to assess their level of adherence to recommendations in the literature with regard to rehabilitation assessment on a conceptual level. A total of 54 responses were received from respondents based in Germany, The Netherlands and the United Kingdom. The results indicate that macroinvertebrate indicators, while widely used in assessing river rehabilitation efforts, exhibited a lower
\end{abstract}

Electronic supplementary material The online version of this article (doi:10.1007/s10750-010-0389-2) contains supplementary material, which is available to authorized users.

Handling editor: S. M. Thomaz

J. Matthews $(\bowtie) \cdot$ B. Reeze

Arcadis Nederland BV, Apeldoorn, The Netherlands

e-mail: Jon.matthews@ @otmail.com

C. K. Feld

Department of Applied Zoology/Hydrobiology, University Duisburg-Essen, Essen, Germany

J. Matthews · A. J. Hendriks

Department of Environmental Science, Radboud

University Nijmegen, Nijmegen, The Netherlands frequency of positive responses than most other indicator types in the short term. Conversely, terrestrial floodplain indicators exhibited the most frequent level of positive response for all ecological type indicators leading to recommendations for further investigations into their use for short-term monitoring. Assessment procedures recommended in literature are largely followed, illustrating the advances that have been made with regard to assessment planning. Indicator responses are influenced by scale factors, for example, land-use and river size, that are often not considered by rehabilitation managers. While an emphasis is placed on ecological, hydrological and morphological indicators in monitoring schemes, the socioeconomic perspective (emphasized in the literature as forming an integral part of the river system) is neglected.

Keywords River - Stream - Rehabilitation ·

Restoration $\cdot$ Monitoring $\cdot$ Indicators

\section{Introduction}

Worldwide, there has been increasing interest in the rehabilitation of freshwater systems in an attempt to mitigate against the effects of long-term degradation. An example of legislative formalization of the rehabilitation philosophy is The European Water Framework Directive (WFD). The WFD sets out 
goals for the attainment of a good ecological status or potential for all surface waters within the European Community to be achieved by the year 2015 (EU, 2000). This target suggests that the success of river rehabilitation projects should be judged with respect to the WFD guidelines.

The WFD recommends monitoring to determine the level of degradation that is present in surface waters (EU, 2000). However, monitoring designed to observe qualities that have developed over decades or even centuries, is not likely to be suitable for the observance of difference in the first few years following a river rehabilitation project (Jahnig, 2007). The ultimate goal of good ecological status may, therefore, take decades to achieve. The variable response of different ecosystem elements also poses challenges for rehabilitation monitoring. River restoration effects reveal spatial and temporal differences in the response of organism groups (Jahnig et al., 2009). In the Kissimmee River project in Florida, it was projected that aquatic plants would recover in 3-8 years, invertebrates in 10-12 years and fish in 12-20 years (Trexler, 1995). This, combined with delays caused by temporal phenomenon such as drought and dispersal, do not cause restoration to fail, but instead, may push response times beyond those over which monitoring is typically funded (Bond \& Lake, 2003). The challenge, therefore, is to identify indicators of progress towards, rather than achievement of the goal of good ecological status. Indicators of progress constitute measurable changes occurring within the first few years following project completion that suggest that a rehabilitated river reach is heading towards the condition of good ecological status.

Indicators of progress are required to demonstrate possibly small changes over a limited duration following rehabilitation interventions. This increases the possibility that scale factors will influence indicator response. Scale factors can include abiotic and biotic 'filters' that interact locally, as well as climatic and geological 'filters' that interact at larger spatial and temporal scales working in a hierarchical fashion (Poff \& Ward, 1990; Levin, 1992; Palmer et al., 2005). In general, recovery appears to be related to stream size (catchment area) and hence colonization opportunities from upstream refuge areas (Friberg et al., 1998; Hansen et al., 1999). Land-use also influences the path of recovery. In un-rehabilitated streams, land-use has been cited as the main driver behind macroinvertebrate composition (Quinn \& Hickey, 1990; Young \& Collier, 2009). Specific to river rehabilitation, land-use stressors may influence the path or block the effects of smaller scale river rehabilitation (Moerke et al., 2004; Entrekin et al., 2009). The scale and type of rehabilitation intervention may also influence indicator response.

In general, where both large- and small-scale constraints occur, effective restoration requires a coordinated attack on both (Palmer et al., 2005). However, rehabilitating all areas of a catchment is unrealistic (Brierley \& Fryirs, 2009), and the influence of land-use, catchment size and temporal factors all affect the condition of rivers and streams, and should be considered when planning rehabilitation (Ekness \& Randhir, 2007). While these type of effects are acknowledged in the literature, little attention has been focused on appraising their influence on indicators of short-term progress following river rehabilitation.

Conceptual elements required for an effective assessment of the results of river rehabilitation include the setting of objectives, initial monitoring prior to rehabilitation interventions, a comparison of the results of initial monitoring with the results of monitoring post implementation and the public reporting of results (Dahm et al., 1995; Bernhardt et al., 2007; Jansson et al., 2007; Woolsey et al., 2007). In reality, assessment is often fragmented, assessing only certain outcomes, avoiding a holistic assessment of ecology, economy and society (Gillilan et al., 2005). Additionally, little agreement exists on what constitutes a successful river restoration effort (Palmer et al., 2005).

The focus of this study is to provide an initial impression of indicator groups that would be most appropriate for use as indicators of progress within the time limits set by the majority of monitoring schemes (5 years). In addition, the effects of scale factors on the results of ecological monitoring following river rehabilitation will be explored. A questionnaire is used to provide further insight into the attitudes of rehabilitation managers to the definition of project success and to explore possible reasons for indicator group choice. Questionnaire responses are used to investigate whether the poor implementation of the conceptual elements of assessment reported in the literature still persist in practice. 


\section{Method}

\section{Literature review}

Data were collected in a literature review and a questionnaire distributed amongst river managers. The literature review aimed to identify indicator groups that demonstrated progress within an initial five monitoring years and allowed an analysis of indicator response with respect to scale factors.

Peer reviewed scientific articles were favoured over other information formats. Papers were selected using the following criteria: (1) the results from the practical assessment of river rehabilitation projects are reported, (2) ecological restoration is a main aim, (3) articles are ideally not published more than 10 years ago and (4) the results of monitoring within 5 years following rehabilitation intervention completion are reported.

Tables were generated, identifying the articles by author and listing scale factor categories that defined the land-use, river size, type of rehabilitation intervention and monitoring duration of each project. If reported separately, the results of articles that contained multiple rehabilitation sites were split into their individual locations.

All individual positive and negative indicator responses within the monitoring results of each article/report were collected and tabulated. A positive indicator response was defined as an indicator response demonstrating progress towards rehabilitation goals within the first 5 years of monitoring. Changes caused directly by interventions themselves, i.e. those involving no evolution away from the initial state created by the interventions, were not included in the analysis. An example of this could be an increase in sinuosity that is a direct result of digging fixed meanders. Any monitoring results that were recorded after the failure of an intervention were also omitted. Statistically insignificant, positive indicator responses were combined with negative responses where statistical analysis was undertaken. An example of statistically insignificant, positive indicator responses would be one where a positive trend was suggested but the sample was too small to provide a significant result. If no statistical analysis was undertaken, for example, where variables were not defined quantitatively, indicators that clearly demonstrated a move towards the objectives of river rehabilitation were assumed to be positive. Negative responses were defined as a cumulative movement away from rehabilitation objectives over the total monitoring period or a complete lack of indicator response.

Once tabulated, positive and negative indicator responses were totalled per indicator group and the number of positive responses expressed as a percentage of the total number of responses found. Subsequently, positive and negative responses within ecological indicator groups were classified according to project river size, land-use, intervention type and monitoring duration scale factors and the results compared for each using bar graphs.

River size was classified qualitatively into the broad subgroups of small, medium and large. These were broad enough to allow the categorization of rivers described in the literature using diverse and qualitative methods, but also allowed a search for trends in the data. A subjective judgment was made using descriptions of catchment size, stream order, channel width measurements at the rehabilitation location, photographs and information obtained from internet sources. The results, therefore, give only an indication of indicator response relating to river size.

Land-use was defined using the following subgroups: urban, agricultural, forestry, limited anthropogenic input and mixed land-use. Projects that suggested a mixture of land-uses were put in a separate mixed land-use category. If required, supplementary information was collected from internet sources.

Rehabilitation interventions were classified into the subgroups of in-channel habitats (ICH), morphological and lateral connectivity. The ICH category consisted of small-scale interventions designed to improve local habitat conditions within the river channel itself e.g. artificial riffles. Morphological interventions were defined as larger scale changes to channel morphology including interventions such as re-meandering and bank and channel re-profiling. The category of lateral connectivity includes interventions that improve the connection between the river channel and its floodplain such as the removal of dikes. All other projects that could not be defined in these categories were allocated to the category 'other'. These involved interventions that, for example, were difficult to categorize spatially such as changes in flow regime that may just involve changes in discharge but may also increase the inundation of 
the floodplain. Positive indicator response was also compared with time to establish if there was an optimum time scale within the first 5 years of monitoring where a majority of indicator groups showed progress.

\section{Questionnaire}

A questionnaire was developed to support and expand the scope of the data obtained from the literature study. Manager's concept of what constitutes a successful rehabilitation project was explored. The concept of success was operationalized using the themes of ecological, learning and stakeholder defined in Palmer et al. (2005). These definitions were supported by Gillilan et al. (2005) and Jansson et al. (2005). This operationalization method was chosen due to its recognition by a variety of authors and its comprehensive nature. Potential project objectives were derived from themes of success as described in Table 1. A coding system was used to facilitate the reporting of results.

Responses were generated from Likert type scales designed to gauge the level of importance that managers attached to each objective in relation to project success ( 1 being of little importance to 5 being very important). Respondents were split into their separate nationalities and analysed statistically to ensure that responses did not vary between countries. Respondent speciality (ecology or nonecology) and the size of river rehabilitation projects were statistically analysed to discover if these characteristics had a bearing on the application of monitoring methods and interpretation of success. The data were non-normal in distribution; therefore, analysis was undertaken using non-parametric statistical tests (Mann-Whitney $U$ test and $\chi^{2}$ test). Finally, the results for individual objectives were combined to identify the relative importance placed on different themes by managers.

The second half of the questionnaire was devoted to discovering if conceptual steps taken to practically assess rehabilitation projects reflect theoretical recommendations. These steps can be summarized as an assessment of the initial state of degradation, development of a reference state, the formulation of objectives and the presence of a monitoring and assessment system (Dahm et al., 1995; Kondolf, 1998; Lake, 2001; Jansson et al., 2005; Palmer et al., 2005; Stoddard et al., 2006; Woolsey et al., 2007).

Table 1 Classification and importance attributed to objectives and themes of success

\begin{tabular}{|c|c|c|c|c|}
\hline Theme & Objective & $\begin{array}{l}\text { Objective } \\
\text { code }\end{array}$ & $\begin{array}{l}\text { No. of } \\
\text { responses }\end{array}$ & Importance $^{\mathrm{a}}$ \\
\hline \multirow[t]{6}{*}{ Ecological success } & $\begin{array}{l}\text { No harm is done to the immediate and wider } \\
\text { ecosystem during rehabilitation interventions }\end{array}$ & E1 & 51 & 5 \\
\hline & $\begin{array}{l}\text { Minimal maintenance to the river section is } \\
\text { required following implementation of measures }\end{array}$ & E2 & 52 & 4 \\
\hline & $\begin{array}{l}\text { The design of rehabilitation interventions is based } \\
\text { on a knowledge of ecological mechanisms }\end{array}$ & E3 & 52 & 5 \\
\hline & Ecological improvements & E4 & 53 & 5 \\
\hline & Geo-morphological improvements & E5 & 53 & 5 \\
\hline & A more natural hydrological regime & E6 & 52 & 5 \\
\hline \multirow[t]{3}{*}{ Learning success } & $\begin{array}{l}\text { The project delivers a scientific contribution that } \\
\text { will benefit future rehabilitation projects }\end{array}$ & L1 & 52 & 4 \\
\hline & There is an increase in management experience & L2 & 52 & 4 \\
\hline & The results of the project assessment are shared with others & L3 & 51 & 5 \\
\hline \multirow[t]{4}{*}{ Stakeholder success } & Increased opportunities for education & $\mathrm{S} 1$ & 51 & 2 \\
\hline & Improved economic opportunities & $\mathrm{S} 2$ & 51 & 1 \\
\hline & Increased opportunities for recreation & $\mathrm{S} 3$ & 50 & 1 \\
\hline & Improvement in aesthetic value & $\mathrm{S} 4$ & 53 & 4 \\
\hline
\end{tabular}

\footnotetext{
${ }^{a}$ Objectives rated for importance to the success of river rehabilitation, mode average ( 1 being of little importance to 5 being very import)
} 
The questionnaire was piloted and then translated to German. Lists of potential respondents with experience in the management of river rehabilitation projects were generated for the United Kingdom $(n=100)$, Germany $(n=100)$ and The Netherlands $(n=20)$. Lists of questionnaire respondents were not taken from projects considered during the literature review. Instead, internet sources, reports, a database held by the UK River Restoration Centre and previous distribution lists were used to provide respondent lists. The respondent lists were analysed for representativeness by assessing if any respondents had worked on the same rehabilitation projects. Three out of the 27 UK respondents were found to have taken part in the same project. This project was extensive, however, covering $7 \mathrm{~km}$ of river over six sites within the UK River Avon catchment. Additionally, these respondents represented different disciplines suggesting that their responses would originate from different perspectives of practice. No German or Dutch respondents were found to have worked on the same projects. Once the questionnaire was sent, three reminders were delivered by email at 2 week intervals to improve response rates.

The data obtained exploring the practical application of the conceptual methodology of river rehabilitation was summarized using content analysis and percentage response.

\section{Results}

\section{Literature review}

The results from the monitoring of 41 rehabilitation projects employing a total of 342 individual indicators were distilled from 239 publications found during the literature study. Details of the total number of indicators analysed related to the number of source articles and reports per indicator group are given in Table 2 .

\section{Indicator groups that demonstrated progress towards rehabilitation goals within an initial five monitoring years}

The largest positive response was demonstrated by non-ecological indicators, with the exception of terrestrial species (Fig. 1). Macroinvertebrates
Table 2 Overview of indicator sources

\begin{tabular}{lll}
\hline Indicator group & $\begin{array}{l}\text { No. of source } \\
\text { articles/ } \\
\text { reports }\end{array}$ & $\begin{array}{l}\text { Total number } \\
\text { of indicators } \\
\text { analysed }\end{array}$ \\
\hline Hydrological & 11 & 46 \\
Terrestrial fauna and flora & 8 & 28 \\
Morphological & 10 & 25 \\
Habitat structure & 19 & 58 \\
Functional & 5 & 10 \\
Fish & 16 & 47 \\
Macrophytes & 8 & 27 \\
Macroinvertebrates & 17 & 73 \\
Physico-chemical & 5 & 27 \\
\hline
\end{tabular}

demonstrated the poorest response of all indicator types with the exception of physico-chemical indicators. In this study, macro-invertebrates were the most frequently utilized indicator of any type for short-term monitoring. Functional indicators demonstrated a relatively frequent positive response; however, this must be viewed with respect to the relatively low sample number. In only one study analysed was an indicator of stakeholder satisfaction applied, no other examples of socioeconomic indicators were found, this group was therefore not included in the bar graph.

\section{Overall response of ecological indicators per river size}

Data comparing river size with the response of ecological indicators (Fig. 2) demonstrate that in the first five monitoring years, the larger the river, the more likely ecological indicators will respond.

\section{Overall response of ecological indicators per land-use type}

The number of positive response varies in a way that reflects the level of stress that the land-use confers on the ecosystem (Fig. 2). More natural systems (forestry and systems characterized by limited anthropogenic influence) appear to respond more slowly or have a more limited response to rehabilitation interventions.

No respondents to the questionnaire reported a consideration of land-use stressors, specifically, in the 
Fig. 1 Indicator response per indicator group within the first five years of monitoring following the completion of rehabilitation interventions

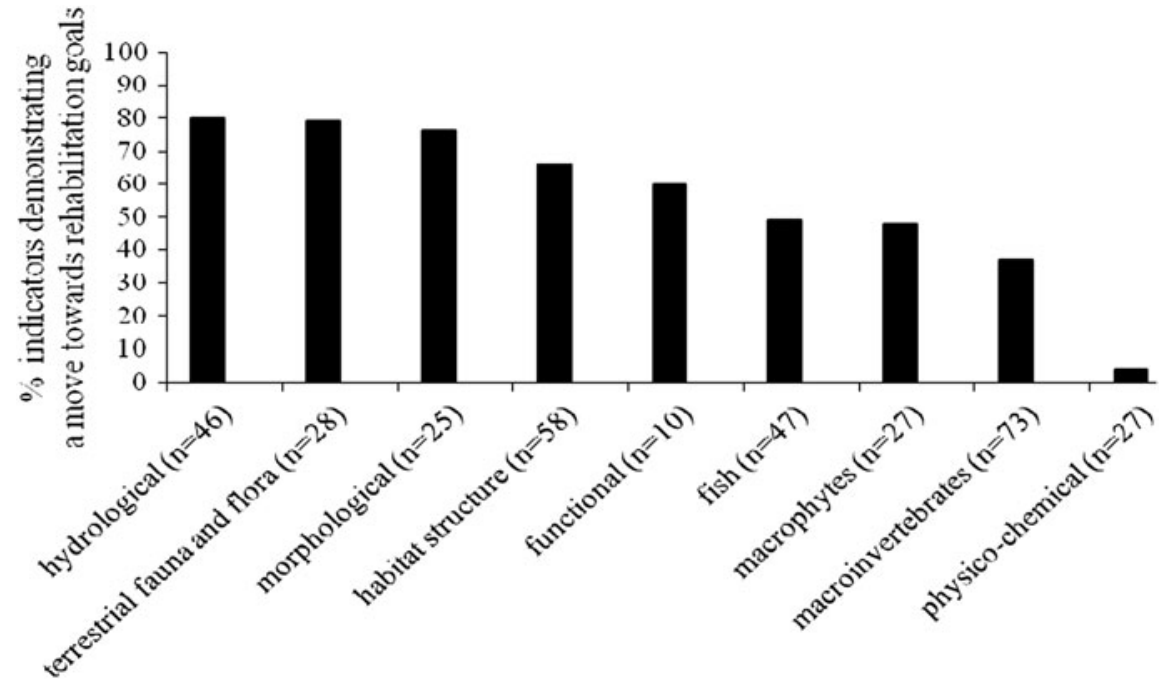

Fig. 2 Ecological indicator response in relation to scale factors within the first five monitoring years following the completion of rehabilitation interventions

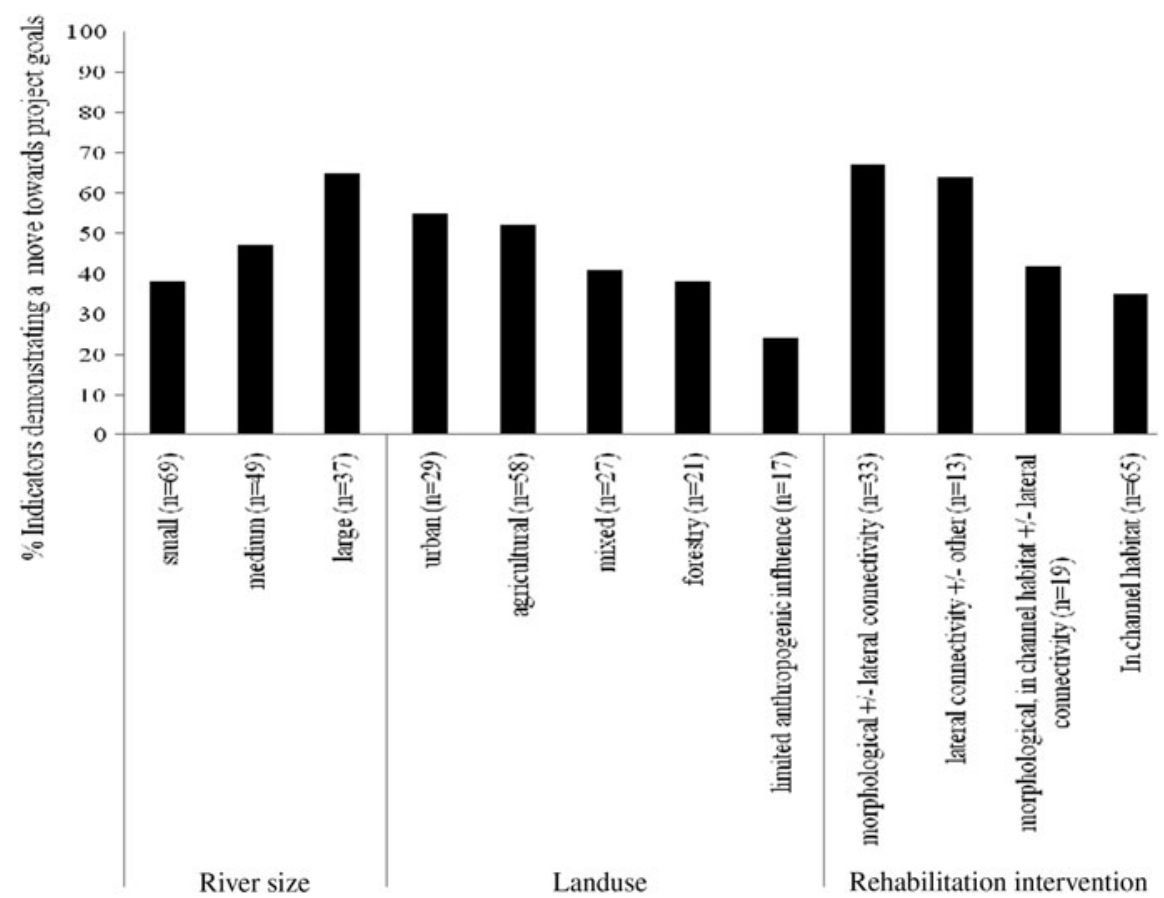

formulation of objectives. Considerations to land-use were related to issues of spatial planning and stakeholder requirements in most cases.

\section{Overall response of ecological indicators per rehabilitation intervention type}

The manipulation of ICH is less likely to produce positive responses in ecological indicators in comparison with other approaches that employ larger scale morphological interventions and reinstatement of lateral connectivity with the floodplain (Fig. 2).

\section{Overall response of ecological indicators} per monitoring year

The variation in the between year data indicates that there is no obvious optimum monitoring duration within 5 years that would provide the most positive 
Fig. 3 Ecological indicator response per monitoring year following the completion of rehabilitation interventions

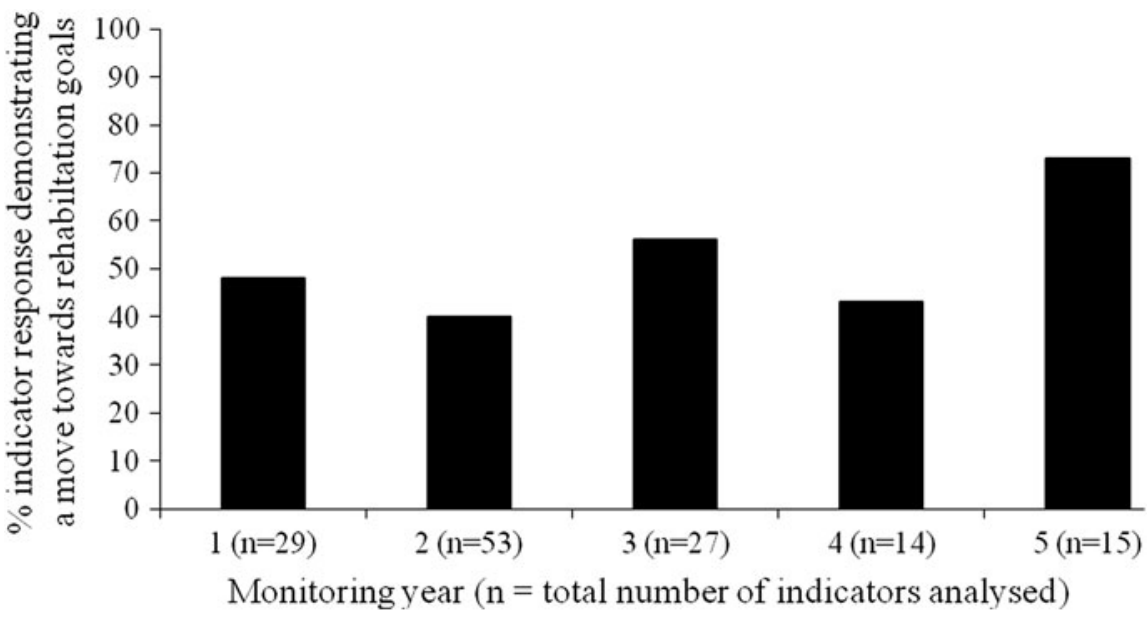

indication of the progression of a rehabilitated river system towards ecological objectives (Fig. 3). The relatively large positive response at 5 years must be viewed in respect of the low number of indicators analysed.

\section{Questionnaire responses}

\section{Importance of themes to project success}

Responses related to the importance of project objectives and respondent characteristics are described in Tables 1 and 3. Analysis demonstrated that ecological objectives were seen by rehabilitation managers as most important to a definition of project success. There was no significant difference observed between respondent specialties or German and British respondents (Table 4).

Ninety-four percent of rehabilitation managers involved stakeholders in the formulation of objectives for river rehabilitation projects $(n=53)$. However, only a small proportion of respondents included an indicator of stakeholder satisfaction in their assessment to gauge the success of their projects (Fig. 4). Objectives that combined to form the stakeholder theme within the questionnaire were rated as being of less importance to the success of rehabilitation projects compared with the learning and ecological themes. There was no significant difference observed between respondent specialties or German and British
Table 3 Respondent characteristics

\begin{tabular}{llllll}
\hline Nationality & $\begin{array}{l}\text { No. of } \\
\text { respondents }\end{array}$ & \multicolumn{2}{l}{ Respondent speciality } & \begin{tabular}{l} 
Mean project size \\
\cline { 3 - 5 } (length in metres)
\end{tabular} \\
\cline { 3 - 5 } Ecological & Non-ecological & No response & \\
\hline German & 23 & 5 & 5 & 13 & 5148 \\
British & 27 & 8 & 8 & 11 & 4214 \\
Dutch & 4 & 0 & 3 & 1 & 5150 \\
\hline
\end{tabular}

Table 4 Mann-Whitney two-tailed analysis of themes of project success, scope of inclusion of spatial elements and respondent characteristics

\begin{tabular}{ccccc}
\hline & Ecological success & Learning success & Stakeholder success & $\begin{array}{c}\text { Scope of inclusion of } \\
\text { spatial elements }\end{array}$ \\
\hline Respondent & $U=78.5, n 1=13$, & $U=75, n 1=13, n 2=16$, & $U=75.5, n 1=13$, & $U=101, n 1=13$, \\
speciality & $n 2=15, P>0.05$ & $P>0.05$ & $n 2=16, P>0.05$ & $n 2=16, P>0.05$ \\
Respondent & $U=244.5, n 1=22$, & $U=218.5, n 1=22$, & $U=226, n 1=22$, & $U=148, n 1=23$ \\
nationality & $n 2=27, P>0.05$ & $n 2=27, P>0.05$ & $n 2=27, P>0.05$ & $n 2=13, P>0.05$ \\
\hline
\end{tabular}


Fig. 4 Percentage of total respondents who reported incorporating particular indicator groups in their monitoring approach

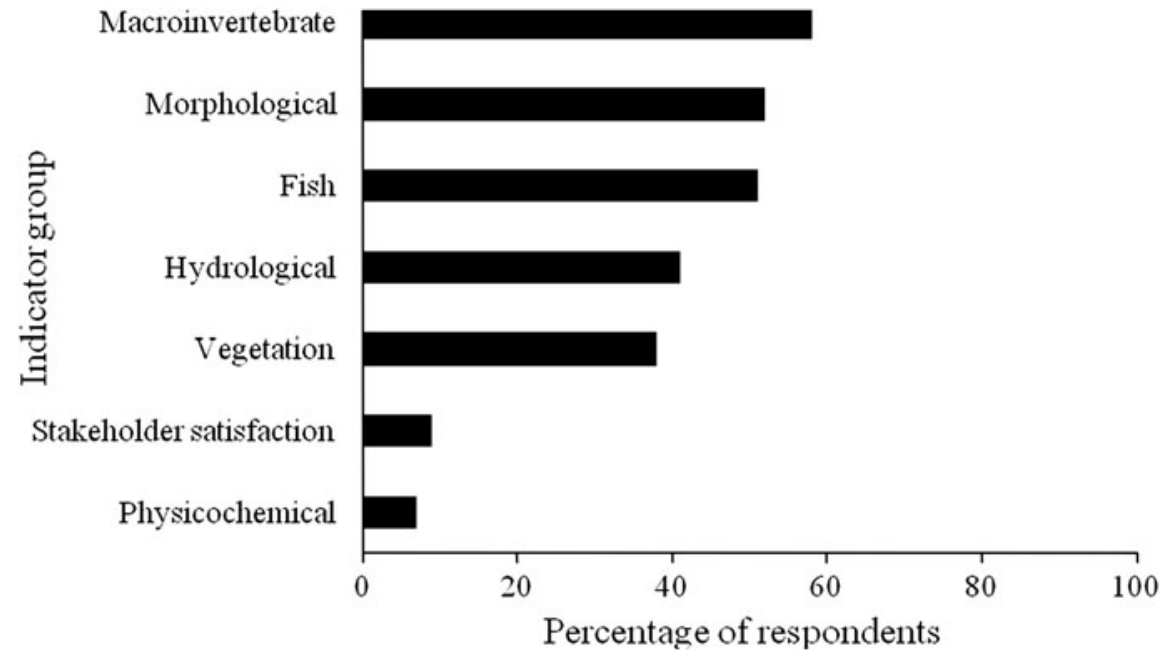

demonstrated to be present in projects carried out in practice (Tables 5, 6). One notable result is the relatively high number of respondents who undertook an assessment of outcomes but neglected to compare monitoring results with project objectives or the initial degradation state. There was no significant difference found between either respondent specialty and project size or the scope of inclusion of spatial elements (Table 4). An analysis examining possible relationships between the application of reference state and respondent specialty was invalidated due to insufficient sample size.

The macroinvertebrate indicator group was used most frequently for project monitoring, whereas socioeconomic and physicochemical type indicators were used the least (Fig. 4). There was no significant
The main conceptual elements of river rehabilitation assessment recommended in the literature were

\section{Comparison of theoretical concepts and practical application}

Table 5 Conceptual elements-initial degradation assessment: inclusion of spatial elements

Table 6 Conceptual elements-other

\begin{tabular}{lllll}
\hline & $\begin{array}{l}\text { River } \\
\text { channel }\end{array}$ & $\begin{array}{l}\text { River channel } \\
\text { and riparian } \\
\text { zone }\end{array}$ & $\begin{array}{l}\text { River channel, } \\
\text { riparian zone } \\
\text { and floodplain }\end{array}$ & $\begin{array}{l}\text { No initial } \\
\text { assessment }\end{array}$ \\
\hline Number of responses analysed & 10 & 16 & 24 & 3 \\
$\%$ Projects where element(s) included & 19 & 30 & 45 & 6 \\
\hline
\end{tabular}

\begin{tabular}{llll}
\hline & $\begin{array}{l}\text { Reference } \\
\text { state }\end{array}$ & Monitoring & $\begin{array}{l}\text { Assessment of outcomes } \\
\text { by comparison with } \\
\text { initial degradation state } \\
\text { or project objectives }\end{array}$ \\
\hline $\begin{array}{l}\text { Number of responses analysed } \\
\% \text { Projects where element included }\end{array}$ & 82 & 47 & 48 \\
\hline
\end{tabular}


difference between respondent specialty and the application of morphological indicators $\chi^{2}(1, N=$ $42)=0.73, P>0.05$. In other cases, however, analysis was not possible due to insufficient sample size.

\section{Discussion}

Methodological limitations

During the research process, a number of methodological limitations were identified. First, it could often not be ascertained whether a lack of indicator response was due to a non-response of the indicator or the result of an ineffective intervention. An example of this is the introduction of river bed material of the wrong grain size when attempting to encourage fish spawning. Also, the influence of other large-scale limiting variables, such as diffuse pollution, might have resulted in a lack of indicator response. The results are therefore expressed in terms of percentage positive indicator response. The use of percentages also introduces negative indicator responses to the analysis. However, the resultant uncertainty is the same for all indicator groups analysed which reduces its influence during group comparisons.

Second, it was sometimes difficult to establish whether a development, particularly related to morphology, demonstrated a positive move towards river rehabilitation goals. Often morphological developments were not evaluated in relation to project goals. Only morphological development that was stated to be a progression towards project objectives or the general goals of river rehabilitation was considered a positive indicator response. This interpretation tends to reduce the number of positive indications taken from literature sources. However, the results demonstrate that morphological response was rated highly suggesting that the influence of this uncertainty is limited.

Indicator groups that demonstrated progress within the initial five monitoring years

Terrestrial flora and fauna indicators gave more positive short-term results following rehabilitation compared to other, within river indicators such as fish and macro-invertebrate indicator groups (Fig. 1). Potential explanations are differing sensitivities relating to water pollution, colonization potential and the presence of habitats in the locality prior to the implementation of rehabilitation interventions (Jahnig et al., 2009). Individuals of most (riverine) taxa move only short distances over their lifetime, this immediately constrains the probability that restored habitat will be colonized, particularly in the short term (Bond \& Lake, 2003). Floodplain inhabitants, on the other hand, have previously been noted to be sensitive to river degradation and rehabilitation. Carabid beetles react negatively to channelisation and floodplain connectivity and floodplain plants may benefit from seed banks which are mobilized if sediment is relocated (Kangas, 1990; Lott, 1996; Hölzel \& Otte, 2001). In general, riparian organism groups may be used as additional parameters to evaluate the short-term effects of restoration, while aquatic organisms may be better suited to reflect long-term effects (Jahnig et al., 2009). In light of these results, the potential for terrestrial species to demonstrate early progress following river rehabilitation should be further investigated with a view to formalizing their use in short-term monitoring schemes.

Macro-invertebrates performed less well in comparison to the majority of other indicator groups. The poor response of macroinvertebrate indicators may be due to the natural variability that is attributed to this group. Natural variation has been demonstrated to reduce the sensitivity of macroinvertebrate indicators to change (Clarke et al., 2006; Blocksom \& Flortmersch, 2008). Variability in relation to space, time and sampling methods have been stated as significant factors that result in difficulties in identifying significant change in macro-invertebrate monitoring (Brooks et al., 2002; Sporka et al., 2006; Haase et al., 2008). The results suggest that macroinvertebrate indicators maybe too insensitive to consistently identify early progress following river rehabilitation interventions. Macroinvertebrates were the most frequently used of all indicator groups in projects examined. The application of this indicator group for short-term monitoring should therefore be re-evaluated.

Non-ecological indicators of rehabilitation success were shown to respond most quickly to the interventions taken to rehabilitate river stretches. However, 
this result should be considered with a note of caution. Morphological changes are dependent on receiving a period of climactic normality including extreme events and/or climactic trends during the monitoring period (Downs \& Kondolf, 2002). Monitoring duration must, therefore, be tailored to the climactic norms of the region under surveillance.

The influence of scale factors on indicator groups

Indicators were observed to respond more positively with increasing river size (Fig. 2). This has also been observed by others. Recovery appears to be related to stream size (catchment area) and hence colonization opportunities from upstream refuge areas (Friberg et al., 1998; Hansen et al., 1999). The dispersal ability of riverine organisms has been implicated as a possible reason for this. With the exception of most insects, and fish in lowland rivers, natural re-colonization of restored sites is only likely to occur from sites within the same stream (Hughes, 2007). The results emphasize the importance of species colonization potential and the presence of local source populations in the choosing of rehabilitation locations.

The influence of land-use on river systems is widely documented. Stream ecosystems are constrained by phenomena acting at different scales in a hierarchical fashion and influences beyond the spatial limits of the project reach will have an effect (Douglas Shields et al., 2007; Schwartz \& Herricks, 2007; Kail \& Hering, 2009). The results suggest that rivers with surrounding land-use that is associated with higher degradation may exhibit a greater potential for early signs of recovery (Fig. 2). An explanation for this could be a lack of distinction between species reflecting a natural reference state and colonization by species that are tolerant of landuse stressors. Tolerant species are able to take advantage of empty niches within initially highly degraded systems following local improvements in habitat quality (Den Hartog et al., 1992; Van der Velde et al., 2002). The poorer response of rehabilitated stretches subject to lesser degrees of land-use stress may also be symptomatic of ecological resilience (Vugteveen et al., 2006). Ecological resilience is characterized by a buffering effect where ecosystems absorb moderate levels of stress before measureable degradation occurs. Caution should also be applied as changes that bring a system in poor condition to good condition maybe more easily detectable and achievable than changes that bring a system in good condition to high condition.

In general, the influence of stressors beyond the boundaries of the restored area should be taken into account during rehabilitation planning, and restoration should occur at the appropriate spatial scale such that restoration is not reversed by the prevailing disturbance regime (Lake et al., 2007). When asked about factors that were considered in the formulation of objectives for river rehabilitation (a question where land-use was given as an example answer), no questionnaire respondents referred to land-use stress in their responses. The influence of spatial factors, such as land-use stress, on monitoring results should therefore be emphasized to the managers of river rehabilitation.

The analysis of response of ecological indicators to rehabilitation intervention type indicated that interventions aimed at improving ICH induced fewer positive indicator responses on their own and in combination with other intervention types (Fig. 2). These observations support the notion that larger scale morphological interventions will produce more positive results from monitoring schemes within 5 years. The involvement of the floodplain in rehabilitation interventions may increase the potential for overall system recovery in the short term by exploiting the recovery potential of terrestrial fauna and flora observed by Jahnig et al. (2009). Larger scale morphological interventions such as re-meandering, if carried out correctly, may have a greater influence on natural habitat provision than smaller scale instream interventions that may also be more temporary in nature due to structural failure (Johnson et al., 2002).

A high degree of variation was observed when all indicator groups were combined and then viewed in terms of percentage positive responses from year to year (Fig. 3). During the initial phase (of rehabilitation), biotic elements and morphology will exhibit large spatial and temporal variation reflecting amongst-year differences in environmental conditions that have little to do with recovery from restoration (Friberg et al., 1998; Muotka et al., 2002; Petranka et al., 2003). This suggests that monitoring should 
continue for longer than 5 years to gain a consistent view of progress towards rehabilitation goals.

Comparison of theory and practice:

the conceptual building blocks of assessment and the interpretation of success

The inclusion of objective setting, assessment of the degradation state, the use of a reference state and monitoring in questionnaire respondent projects suggests that river managers have taken note of past criticisms relating to the lack of proper assessment within river rehabilitation projects (Tables 5, 6). A potential area for improvement is in project assessment where $27 \%$ of respondents reported that an assessment was undertaken but monitoring results were not compared with project objectives or an initial degradation state.

Respondents reported that monitoring was undertaken in the majority of rehabilitation projects, contrasting with statements made in the literature. However, lack of standardization in project reporting and monitoring continues to hamper abilities to compare and analyse the outcomes of similar projects. The importance of standardisation has been emphasized as a determining factor in the effectiveness of river restoration (Gretchen \& Allan, 2006). Respondents emphasized, however, the importance of knowledge sharing to the success of river rehabilitation suggesting that practitioners would be open to efforts to standardize assessment in the future.

An important observation that was made during the study was the lack of formal assessment of the achievement of stakeholder and learning objectives during project assessment. This is reflected in the relative lack of importance placed on the stakeholder theme (Table 1) and supports separate observations that criticise the lack of holistic assessments in river rehabilitation (Gillilan et al., 2005). Rivers cannot be considered as systems that are isolated from the surrounding human population, and society should be included in assessments of river condition. River system health has been defined as an expression of a river's ability to sustain its ecological functioning (vigour and resilience) in accordance with its organization while allowing social and economic needs to be met by society (Vugteveen et al., 2006). The inclusion of socioeconomic elements to provide a holistic view of river systems is supported by others
(Leuven et al., 2000; Lenders \& Knippenberg, 2005). In a more practical sense, socioeconomic elements are seen to permeate the planning and execution of river rehabilitation. Decisions related to river rehabilitation have to take into account trade-offs between ecological goals, ecosystem services, competing land-uses and costs (Reichert et al., 2007). Rehabilitation managers should, therefore, consider the relevance of socioeconomic factors and formulate objectives and indicators to measure success in relation to their projects.

Acknowledgments Thanks go to Prof. Dr. Daniel Hering, Rico Gerfen, Mirjam De Groot and Kathrin Januschke for their technical assistance. Special thanks go to Martin Janes and Nick Elbourne at the River Restoration Centre in the UK for their assistance in providing lists of respondents for the questionnaire.

Open Access This article is distributed under the terms of the Creative Commons Attribution Noncommercial License which permits any noncommercial use, distribution, and reproduction in any medium, provided the original author(s) and source are credited.

\section{References}

Bernhardt, E. S., E. B. Sudduth, M. A. Palmer, J. D. Allan, J. L. Meyer, G. Alexander, J. Follastad-Shah, B. Hassett, R. Jenkinson, R. Lave, J. Rumps \& L. Pagano, 2007. Restoring rivers one reach at a time: results from a survey of U.S. river restoration practitioners. Restoration Ecology 15: 482-493.

Blocksom, K. A. \& J. E. Flortmersch, 2008. Field and laboratory performance characteristics of a new protocol for sampling riverine macroinvertebrate assemblages. River Research and Applications 24: 373-387.

Bond, N. R. \& P. S. Lake, 2003. Local habitat restoration in streams: constraints on the effectiveness of restoration for stream biota. Ecological Management \& Restoration 4: 193-198.

Brierley, G. \& K. Fryirs, 2009. Don't fight the site: three geomorphic considerations in catchment scale river rehabilitation planning. Environmental Management 43: 1201-1218.

Brooks, S. S., M. A. Palmer, B. J. Cardinale, C. M. Swan \& S. Ribblett, 2002. Assessing stream ecosystem rehabilitation: limitations of community structure data. Restoration Ecology 10: 156-168.

Clarke, R. T., A. Lorenz, L. Sandin, A. Schmidt-Kloiber, J. Strackbein, N. T. Kneebone \& P. Haase, 2006. Effects of sampling and sub-sampling variation using the STARAQEM sampling protocol on the precision of macroinvertebrate metrics. Hydrobiologia 566: 441-459. 
Dahm, C. N., K. W. Cummins, H. M. Valett \& R. L. Coleman, 1995. An ecosystem view of the restoration of the Kissimmee River. Restoration Ecology 3: 225-238.

Den Hartog, C., F. W. B. Van den Brink \& G. Van der Velde, 1992. Why was the invasion of the River Rhine by Corophium curvispinum and Corbicula species so successful? Journal of Natural History 26: 1121-1129.

Douglas Shields, F., S. S. Knight \& C. M. Cooper, 2007. Can warm water streams be rehabilitated using watershed scale standard control measures alone? Environmental Management 40: 62-79.

Downs, P. W. \& G. M. Kondolf, 2002. Post-project appraisals in adaptive management of river channel restoration. Environmental Management 29: 477-496.

Ekness, P. \& T. Randhir, 2007. Effects of riparian areas, stream order, and land use disturbance on watershedscale habitat potential: an ecohydrological approach to policy. Journal of the American Water Resources Association 43: 1468-1482.

Entrekin, S. A., J. L. Tank, E. J. Rosi-marshall, T. J. Hoellein \& G. A. Lamberti, 2009. Response of secondary production by macroinvertebrates to large wood addition in three Michigan streams. Freshwater Biology 54: 1741-1758.

European Union (EU), 2000. Directive 2000/60/EC of the European parliament and of the council of 23 October 2000 establishing a framework for community action in the field of water policy. [http://eurlex.europa.eu/ LexUriServ/LexUriServ.do?uri=CELEX:32000L0060:EN: NOT].

Friberg, N., B. Kronvang, H. O. Hansen \& L. M. Svendsen, 1998. Long-term, habitat-specific response of a macroinvertebrate community to river restoration. Aquatic Conservation: Marine and Freshwater Ecosystems 8: 87-99.

Gillilan, S., K. Boyd, T. Hoitsma \& M. Kauffman, 2005. Challenges in developing and implementing ecological standards for geomorphic river restoration projects: a practitioner's response to Palmer et al. (2005). Journal of Applied Ecology 42: 223-227.

Gretchen, G. A. \& J. D. Allan, 2006. Stream restoration in the Upper Midwest, USA. Restoration Ecology 14: 595-604.

Haase, P., S. U. Pauls, H. M. Engelhardt \& A. Sundermann, 2008. Effects of sampling microhabitats with low coverage within the STAR/AQEM macroinvertebrate sampling protocol on stream assessment. Limnologica 38: $14-22$.

Hansen et al., 1999 cited in: Pederson, M. L., N. Friberg, J. Skrivers, A. Baattrup-Pederson \& S. E. Larsen, 2007. Restoration of Skern River and its valley-short-term effects on river habitats, macrophytes and macroinvertebrates. Ecological Engineering 30: 145-156.

Hölzel, N. \& A. Otte, 2001. The impact of flooding regime on the soil seed banks of flood-meadows. Journal of Vegetation Science 12: 209-218.

Hughes, J. M., 2007. Constraints on recovery: using molecular methods to study connectivity of aquatic biota in rivers and streams. Freshwater Biology 52: 616-631.

Jahnig, S., 2007. Comparison between multiple-channel and single-channel stream sections - hydromorphology and benthic macroinvertebrates. $\mathrm{PhD}$ Thesis, University of Duisburg-Essen, Essen, Germany.

Jahnig, S. C., S. Brunzel, S. Gacek, A. W. Lorenz \& D. Hering, 2009. Effects of re-braiding measures on hydromorphology, floodplain vegetation, ground beetles and benthic invertebrates in mountain streams. Journal of Applied Ecology 46: 406-416.

Jansson, R., H. Backx, A. J. Boulton, M. Dixon, D. Dudgeon, F. M. R. Hughes, K. Nakamura, E. H. Stanley \& K. Tockner, 2005. Stating the mechanisms and refining criteria for ecologically successful river restoration: a comment on Palmer et al. (2005). Journal of Applied Ecology 42: 218-222.

Jansson, R., C. Nilsson \& B. Malmqvist, 2007. Restoring freshwater ecosystems in riverine landscapes: the roles of connectivity and recovery processes. Freshwater Biology 52: $589-596$

Johnson, P. A., R. L. Tereska \& E. R. Brown, 2002. Using technical adaptive management to improve design guidelines for urban instream structures. Journal of the American Water Resource Association 38: 1143-1152.

Kail, J. \& D. Hering, 2009. The influence of adjacent stream reaches on the local ecological status of central European mountain streams. River Research and Application 25: $537-550$.

Kangas, 1990 cited in: Boscaini, A., A. Franceschini \& A. Maiolini, 2000. River ecotones: carabid beetles as a tool for quality assessment. Hydrobiologia 422: 173-181.

Kondolf, G. M., 1998. Lessons learned from river restoration projects in California. Aquatic Conservation: Marine and Freshwater Ecosystems 8: 39-52.

Lake, P. S., 2001. On the maturing of restoration: linking ecological research and restoration. Ecological Management and Restoration 2: 110-115.

Lake, P. S., N. Bond \& P. Reich, 2007. Linking ecological theory with stream restoration. Freshwater Biology 52: 597-615.

Lenders \& Knippenberg, 2005 cited in: Vugteveen, P., R. S. E. W. Leuven, M. A. J. Huijbregts \& H. J. R. Lenders, 2006. Redefinition and elaboration of river ecosystem health: perspective for river management. Hydrobiologia 565: 289-308.

Leuven et al., 2000 cited in: Vugteveen, P., R. S. E. W. Leuven, M. A. J. Huijbregts \& H. J. R. Lenders, 2006. Redefinition and elaboration of river ecosystem health: perspective for river management. Hydrobiologia 565: 289-308.

Levin, S. A., 1992. The problem of pattern and scale in ecology. Ecology 73: 1943-1967.

Lott, 1996 cited in: Boscaini, A., A. Franceschini \& A. Maiolini, 2000. River ecotones: carabid beetles as a tool for quality assessment. Hydrobiologia 422: 173-181.

Moerke, A. H., K. J. Gerard, J. A. Latimore, R. A. Hellenthal \& G. A. Lamberti, 2004. Restoration of an Indiana, USA, stream: bridging the gap between basic and applied lotic ecology. Journal of the North American Benthological Society 23: 647-660.

Muotka, T., R. Paavola, A. Haapala, M. Novikmec \& P. Laasonen, 2002. Long-term recovery of stream habitat structure and benthic invertebrate communities from 
in-stream restoration. Biological Conservation 105: 243-253.

Palmer, M. A., E. S. Bernhardt, J. D. Allan, P. S. Lake, G. Alexander, S. Brooks, J. Carr, S. Clayton, C. N. Dahm, J. Follstad Shah, D. L. Galat, S. G. Loss, P. Goodwin, D. D. Hart, B. Hassett, R. Jenkinson, G. M. Kondolf, R. Lave, J. L. Meyer, T. K. O'Donnell, L. Pagano \& E. Sudduth, 2005. Standards for ecologically successful river restoration. Journal of Applied Ecology 42: 208-217.

Petranka, J. W., S. S. Murray \& C. A. Kennedy, 2003. Responses of amphibians to restoration of a southern Appalachian wetland: perturbations confound post-restoration assessment. Wetlands 23: 278-290.

Poff, N. L. \& J. V. Ward, 1990. Physical habitat template of lotic systems: recovery in the context of historical pattern of spatiotemporal heterogeneity. Environmental Management 14: 629-645.

Quinn, J. M. \& C. W. Hickey, 1990. Characterisation and classification of benthic invertebrate communities in 88 New Zealand rivers in relation to environmental factors. New Zealand Journal of Marine and Freshwater Research 24: 387-409.

Reichert, P., M. Borsuk, M. Hostmann, S. Schweizer, C. Sporri, K. Tockner \& B. Truffer, 2007. Concepts of decision support for river rehabilitation. Environmental Modelling and Software 22: 188-201.

Schwartz, J. S. \& E. E. Herricks, 2007. Evaluation of poolriffle naturalization structures on habitat complexity and the fish community in an urban Illinois stream. River Research and Applications 23: 451-466.

Sporka, F., H. E. Vlek, E. Bulankova \& I. Krno, 2006. Influence of seasonal variation on bio-assessment of streams using macroinvertebrates. Hydrobiologia 566: 543-555.

Stoddard et al., 2006 cited in: Woolsey, S., F. Capelli, T. Gonser, E. Hoehn, M. Hostmann, B. Junker, A. Paetzold, C. Roulier, S. Schweizer, S. D. Tiegs, K. Tockner, C. Weber \& A. Peter, 2007. A strategy to assess river restoration success. Freshwater Biology 52: 752-769.

Trexler, J. C., 1995. Restoration of the Kissimmee river - a conceptual model of past and present fish communities and its consequences for evaluating restoration success. Restoration Ecology 3: 195-210.

Van der Velde et al., 2002 cited in: Bij de Vaate, A., A. G. Klink, M. Greijdanus-Klaas, L. H. Jans, J. Oosterbann \& F. Kok, 2007. Effects of habitat restoration on the macroinvertebrate fauna in a foreland along the River Waal, the main distributary in the Rhine Delta. River Research and Applications 23: 171-183.

Vugteveen, P., R. S. E. W. Leuven, M. A. J. Huijbregts \& H. J. R. Lenders, 2006. Redefinition and elaboration of river ecosystem health: perspective for river management. Hydrobiologia 565: 289-308.

Woolsey, S., F. Capelli, T. Gonser, E. Hoehn, M. Hostmann, B. Junker, A. Paetzold, C. Roulier, S. Schweizer, S. D. Tiegs,
K. Tockner, C. Weber \& A. Peter, 2007. A strategy to assess river restoration success. Freshwater Biology 52: 752-769.

Young, R. G. \& K. J. Collier, 2009. Contrasting responses to catchment modifications among a range of functional and structural indicators of river ecosystem health. Freshwater Biology 54: 2155-2170.

\section{Author Biographies}

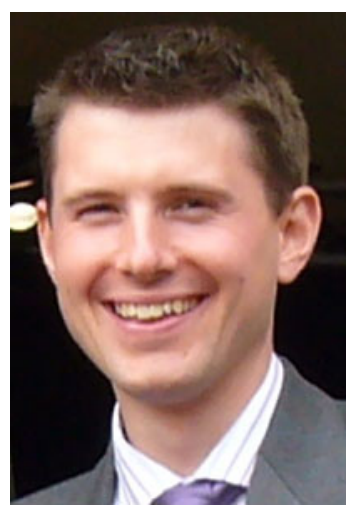

Jonathan Matthews studied Environmental Science at Manchester Metropolitan University, UK, and has recently received an Environmental Science Master degree achieving Bene Meritum from Radboud University, Nijmegen, The Netherlands. Specialising in water management, Jonathan has been involved in research into the distribution of invasive freshwater Dreissena species and has worked at Arcadis Environmental Consultancy where he undertook research into the monitoring and assessment of river rehabilitation projects. Currently he is working as a junior researcher at the Alterra Research Institute in Wageningen, The Netherlands, examining the evidence base supporting methods applied in the rehabilitation of rivers.

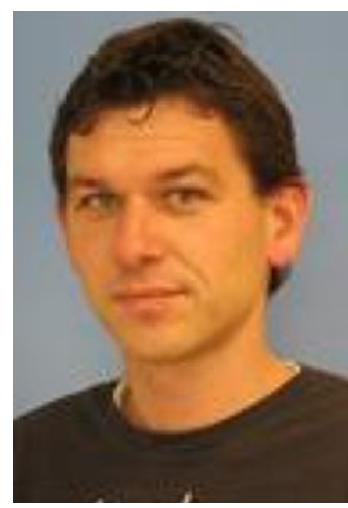

Bart Reeze is a senior aquatic ecologist at the consultancy firm Arcadis in The Netherlands. Following his education in 'ecological water management' at Wageningen University, he worked at the Dutch Institute for Water Management and Waste Water Treatment (RIZA). As a specialist in water quality and aquatic ecology, he has dealt with projects on biological monitoring and the setting of environmental objectives for large lakes and rivers, often related to the European Water Framework Directive. Within Arcadis, he has developed as an all-round consultant on water quality and aquatic ecology, dealing with topics such as bluegreen algae, fish migration and the rehabilitation of rivers and lakes. 


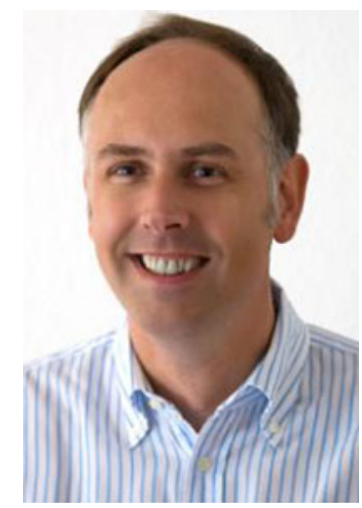

Christian K. Feld is a senior researcher at the University of DuisburgEssen in Essen, Germany. $\mathrm{He}$ is a lecturer for freshwater ecology and protection within the master program 'Transnational ecosystembased Water Management' (TWM). From 1991 until 1997, Christian K. Feld studied zoology, nature protection, ecology and geography at the University of Marburg, Germany, and graduated with a diploma degree in biology. He finished his graduate study at the Institute of Freshwater Ecology and Inland Fisheries in Berlin, Germany, on the colonization of dead wood in the River Spree. In 2000, he began his PhD study on novel multimetric assessment systems for lowland rivers using benthic invertebrates at the University of Duisburg-Essen. He has been involved in several European and national research projects on the implementation of the Water Framework Directive and is now co-leading a large research project on the assessment and management of coastal, transitional and fresh waters. His major fields of interest are the role of biodiversity in river ecosystem functioning and the development of ecologically successful river restoration.

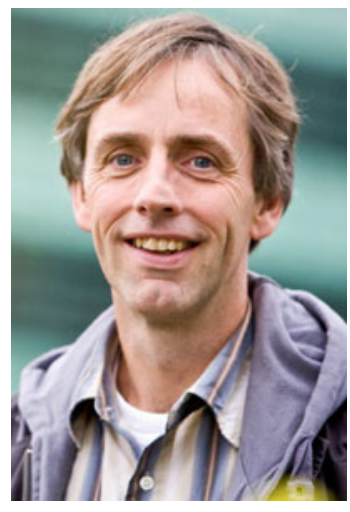

A. Jan Hendriks has been involved in international research and management of river deltas at various positions. $\mathrm{He}$ currently holds a chair in Environmental Science at Radboud University, Nijmegen. His main interest is in multiple stressor assessments, aimed at understanding and predicting the combined impact of physical and chemical pressures on populations and communities. To that end, modelling and monitoring tools are used. 